\title{
Optimal Allocation and Size Selection of Dispersed Generation in Radial Distribution System
}

\author{
Aditya Prasad Padhy ${ }^{1}$ \\ Department of Electrical Engineering \\ Kalinga University, \\ Raipur, Chhattisgarh, India
}

\author{
Manisha Bhatt ${ }^{2}$ \\ Department of Electrical Engineering \\ Kalinga University, \\ Raipur, chhattisgarh, India
}

\begin{abstract}
This paper contributes an analytical technique for the allocation and size selection of dispersed generations (DGs) in radial distributed system (DS)). The proposed technique is computationally expeditious as compared to other existing techniques. The prime objective of this method is to improve voltage profile at each node and reduce total active power loss in 33- bus radial distribution system (RDS). Voltage stability indicator (VSI) is used to find heavily loaded bus in the system. After finding the heavily loaded bus, it is set as optimal location for placement of DG. At this optimal location, the size of DG is determined by using continuous increment of step size (CISS) technique. The effectiveness of the proposed technique is validated from simulated results, by comparing voltage profile, branch current and power losses with the presence and absence of DG.
\end{abstract}

Keywords: Radial distribution system, dispersed generation, optimal allocation, voltage stability indicator, continous increment of step size.

\section{INTRODUCTION}

In recent era, Distribution system (DS) is added as an integral part of power distribution system [1]. The indispensible growth of power demand has increased the role and importance of DS. To encounter the load demand effectively, several changes occur in DS resulting in establishment of complex distribution structure. One of the most important changes in DS structure is invasion of renewable energy in the system. These invasions are known as dispersed generations (DGs). The involvement of DGs in the system affect DS such as: minimization of power loss, improvement of node voltage, and reliability [2]. Thus, DS in accordance with DG is the most prominent part of research domain.

Most of the DS structures are radial in nature in which power flows in a single way from the distribution substation to the consumer [3]. Radial distribution system (RDS) has high $R / X$ ratio, radial structure, and unbalance conditions of load where $R$ and $X$ are the resistance and reactance of line respectively. High $R / X$ ratio leads to high power loss and more voltage drops. In RDS nodes, sudden voltage drops occurs under critical loading conditions. In transmission system, load flow by traditional methodologies has serious convergence problems due to the high $R / X$ ratio of the RDS. For proper RDS planning, an efficient load flow technique is required. Hence, these methodologies are substituted by the available methods for load flow of distribution system as backward forward [4] and direct approach methods [5]. These methods have the advantages of quick convergence and less computation time.

In conventional system, renewable energy invasion has increased in earlier years due to environmental concerns. The conventional generation resources such as thermal, hydro, nuclear, etc. are being penetrated by small-scale generations like photovoltaic (PV), wind, and fuel cell. Although these DGs have very less capacity (Range: $1 \mathrm{KW}$ to $50 \mathrm{MW}$ ) compared to other conventional resources, availability of these resources minimize power loss, improves voltage profile [6]. Therefore, DGs are required for optimal sizing and proper location.

Many researchers have found proper solution of optimal sizing and location issues of DGs in DS. Genetic algorithm (GA) is implemented to solve the metaheurstic optimization problem for location and size selection of DG [7]. The technique used in [8] minimizes the fitness function using GA for power loss minimization. In general, constant power models are considered in the DS. But in [9], different load models i.e. residential, commercial and industrial are carried out in RDS while optimally allocating and sizing DGs using GA. A hybridized GA and simulated annealing (SA) algorithm is implemented to compute optimal location of DG in [10]. A mixed GA-particle swarm optimization (GA-PSO) algorithm is mentioned in [11] to find out the optimal location and sizing of DG. In [12, 13], binary PSO and fuzzy embedded GA techniques are proposed for optimal DS planning in presence of DGs. The problem of optimal DS planning with DGs in [14] is treated by means of multiobjective PSO (MOPSO). A MOPSO approach is employed to deal with problem considering different load models in [15]. Artificial bee colony (ABC) algorithm is employed to determine the optimal allocation, size and power factor in order to minimize active power loss [16]. Bacterial foraging algorithm (BFA) is implemented to find the optimal size of DG [17]. In [18], backtracking search algorithm (BSA) is used to assign DGs in DS. An immune algorithm (IA) is formulated to solve the optimal DG planning problem in smart grid [19]. Modified teaching-learning based algorithm (MTLBA) is proposed in [20] to compute the optimal allocation and size of the DG units in RDS. 
Although numerous techniques are available for optimal location and sizing of DG, but traditional techniques are still a current interest. Thus, this article presented a voltage stability indicator (VSI) which indicates the heavily loaded bus. This bus signifies the optimal location of DG placement. After proper allocation of DG, the size of DG is found out by continuous increment of step size (CISS) technique. CISS technique is applied to monitor active and reactive power loss in the IEEE-33bus system.

The paper is organized as follows: In section 2, presents load flow equations and power loss computation for 33 bus RDS. Proposed methodology for optimal allocation and size selection of DG are explained in Section 3, Section 4 discusses the 33 bus test system and simulation results. Finally, conclusion is outlined in section 5 .

\section{PROBLEM FORMULATION}

\section{A. Radial distribution load flow}

In [5] author proposed a simplified and efficient technique for radial distribution system (RDS). A simplified RDS shown in Fig. 1.

The equivalent load current injection, corresponding to power injection equations

$I_{\alpha}=\left(P_{\alpha+1}+j Q_{\alpha+1} / V_{\alpha+1}\right)^{*} \quad \alpha=1,2,3, \cdots$.

For the branch connecting buses 1 to 4 , the branch currents calculated using $\mathrm{KCL}$ as

$G_{1}=I_{2}+I_{3}+I_{4}$

$G_{2}=I_{3}+I_{4}$

$G_{3}=I_{4}$

Branch injection Matrix (BIM) becomes

$\left[\begin{array}{l}G_{1} \\ G_{2} \\ G_{3}\end{array}\right]=\left[\begin{array}{lll}1 & 1 & 1 \\ 0 & 1 & 1 \\ 0 & 0 & 1\end{array}\right]\left[\begin{array}{l}I_{2} \\ I_{3} \\ I_{4}\end{array}\right]$

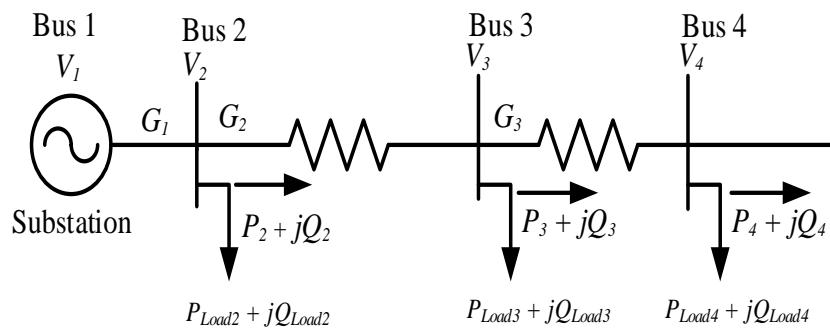

Fig. 1. Single line diagram of radial distribution system In general form,

$[G]=[\mathrm{BIM}][I]$

Node voltages at different buses calculated by using KVL

$V_{\alpha+1}=V_{\alpha}-G_{\alpha} Z_{\alpha, \alpha+1}$

Power loss in between the buses $\alpha$ and $\alpha+1$ is calculated as $P_{L}(\alpha, \alpha+1)=(I)_{\alpha}^{2} * R_{\alpha}$

The total power loss of the RDS is computed by the summation of all the branch losses, which is represented by
Total power loss $P_{T L}=\sum_{\alpha=1}^{t b} P_{L}(\alpha, \alpha+1)$

where, " $t b$ " represents total number of buses.

\section{PROPOSED METHODOLOGY}

In distribution system, the node voltage plays a important role to maintain good voltage regulation. Ideally, voltage regulation should be nearly equal to zero, but due to line resistance and reactance there are slight drop in voltage in different nodes of the RDS. To improve voltage profile and reduce line losses, different DGs are used at different power factor [21] according to the requirement as shown in table

\section{A. Voltage stability node indicator for dg placement}

To identify the most sensitive or heavily loaded bus in the system, voltage stability node indicator (VSNI) is used

From figure 1 branch current is given by

$\left(I_{\alpha}\right)^{2}=\left(\frac{\left(P_{\alpha+1}\right)^{2}+\left(Q_{\alpha+1}\right)^{2}}{\left(V_{\alpha+1}\right)^{2}}\right)$

Active and reactive power loss of the branch between two nodes is computed by using following equation

$$
P_{L}=r\left(\frac{\left(P_{\alpha+1}\right)^{2}+\left(Q_{\alpha+1}\right)^{2}}{\left(V_{\alpha+1}\right)^{2}}\right)
$$

TABLE-1 DG SCENARIO

\begin{tabular}{|c|c|c|c|}
\hline $\begin{array}{c}\text { Types of } \\
\text { DG }\end{array}$ & $\begin{array}{c}\text { Power factor } \\
\text { (P.F) }\end{array}$ & $\begin{array}{c}\text { Power injection } \\
\text { ability }\end{array}$ & Examples \\
\hline $\bar{A}$ & P. $F_{D G}=0$ & Only reactive power & $\begin{array}{l}\text { Synchronous } \\
\text { compensator }\end{array}$ \\
\hline B & P. $F_{D G}=1$ & Only active power & $\begin{array}{c}\text { Photovoltaic } \\
\text { system }\end{array}$ \\
\hline $\mathrm{C}$ & $0<\mathrm{P} . \mathrm{F}_{\mathrm{DG}}<1$ & $\begin{array}{l}\text { Both Active and } \\
\text { reactive power }\end{array}$ & $\begin{array}{c}\text { Synchronous } \\
\text { generator }\end{array}$ \\
\hline $\mathrm{D}$ & $0<\mathrm{P} . \mathrm{F}_{\mathrm{DG}}<1$ & $\begin{array}{c}\text { Active power and } \\
\text { consuming reactive } \\
\text { power }\end{array}$ & Wind turbine \\
\hline
\end{tabular}

$$
P_{L}=x\left(\frac{\left(P_{\alpha+1}\right)^{2}+\left(Q_{\alpha+1}\right)^{2}}{\left(V_{\alpha+1}\right)^{2}}\right)
$$

From the above (9) and (10) the developed VSNI is given by

$$
V S N I=\frac{\sqrt[4]{\left(\left(P_{\alpha+1}\right)^{2}+\left(Q_{\alpha+1}\right)^{2}\right)}}{\left(V_{\alpha+1}\right)^{2}} \leq 1
$$


From (11) it can be cleared that $0 \leq V S N I \leq 1$. Further, when the value of the VSNI approaches to 1.0, the system will become its unstable. Similarly, the values away from zero indicates improved stability of the system.

\section{B. Optimal size selection using Continuous increment of step size (CISS)}

Once the optimal location of DG is fixed, then DG size change from 0 to 1 p.u. of the total load. As the DG size increases, total active power is injected to the system increases. This injected power minimizes the total active power loss. A parabolic curve is formed between DG size and total active power loss. This curve indicates, first the losses of the system decreases till it reaches the optimum point. Thereafter, system losses suddenly increases. Thus, step size plays factor while selecting DG size. In present scenario, the step size chosen is $0.1 \mathrm{Mw}$. For exact DG size, step size must be as small as possible, but the simulation time increases.

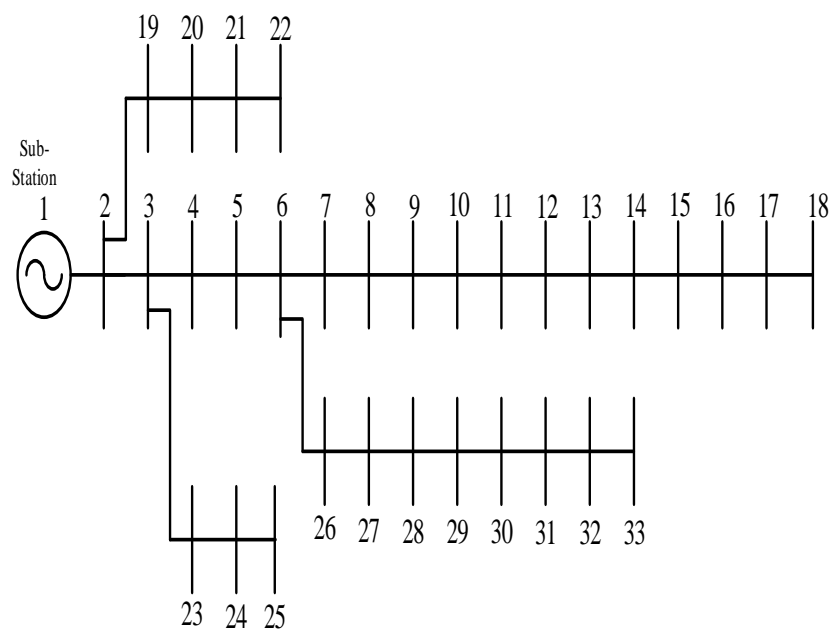

Fig. 2. Single line diagram of 33-bus radial distribution system

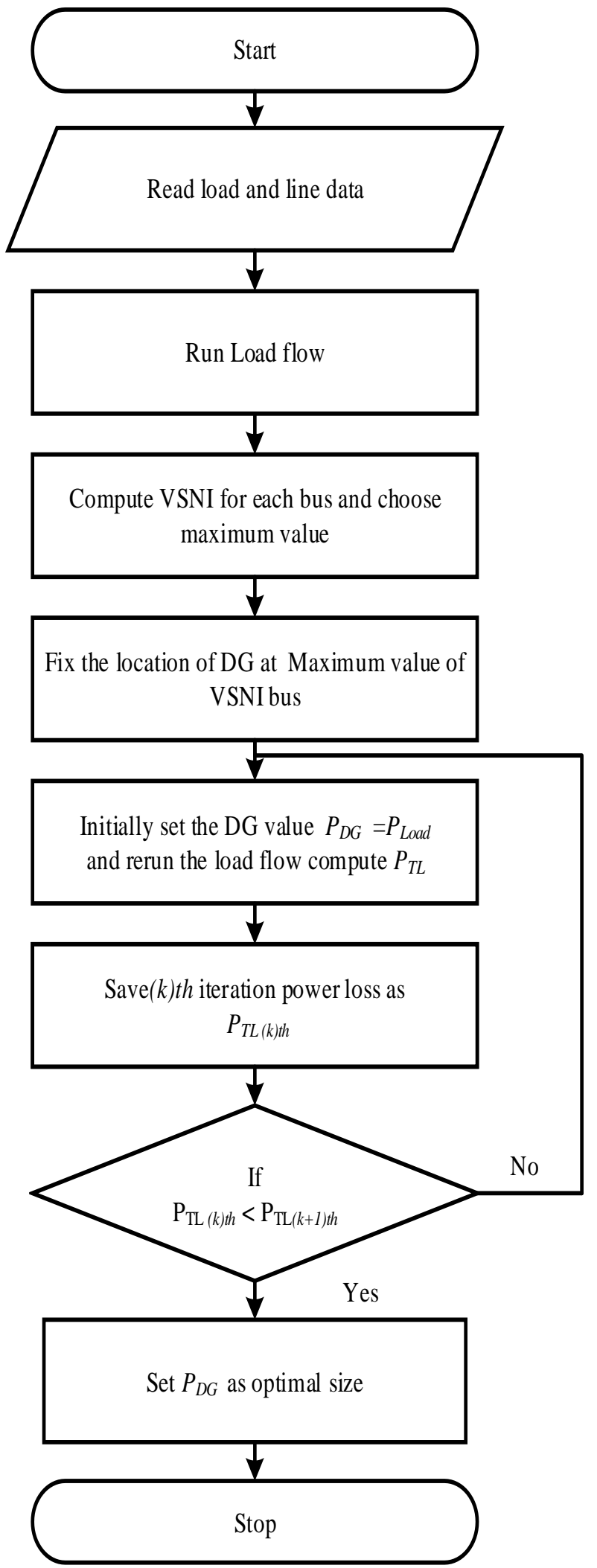

Fig. 3. Flow chart for proposed methodology 


\section{RESULT AND DISCUSSIONS}

The Fig. 3 shows the single line diagram of 33 bus radial distribution system. The detailed methodology of the proposed method is described by flow chart as shown in Fig. 2. The proposed flow chart described in two steps. At First, optimal location of DGs are calculated by using VSNI. The tabulated values of VSIN are shown in table 1 . The table 1 indicates the active and reactive power consumed by different buses and their corresponding VSNI values. In next step, the optimal size of the DGs are determined by using continuous increment of step size (CISS) technique with a step size of $0.1 \mathrm{Mw}$.

\section{A. Case A (DG placement at bus no: 25)}

In this case DGs are connected at bus no 25. From the Fig. 4 it is noticed that, active power loss of the system increases, when the DG size increases beyond an optimum point.

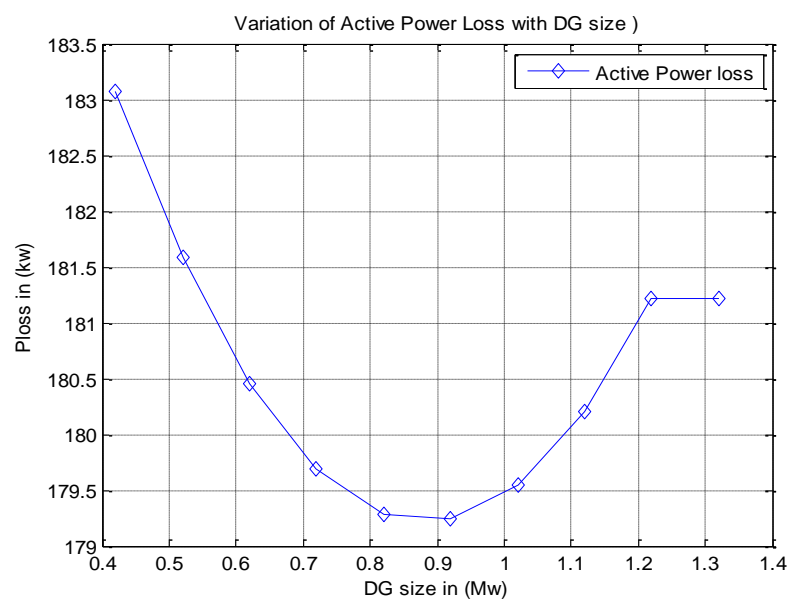

Fig. 4. Power loss curve with step increment of DG size at bus no. 25

Optimal point is calculated based on values of voltage stability node indicator, which is shown in Table. 2

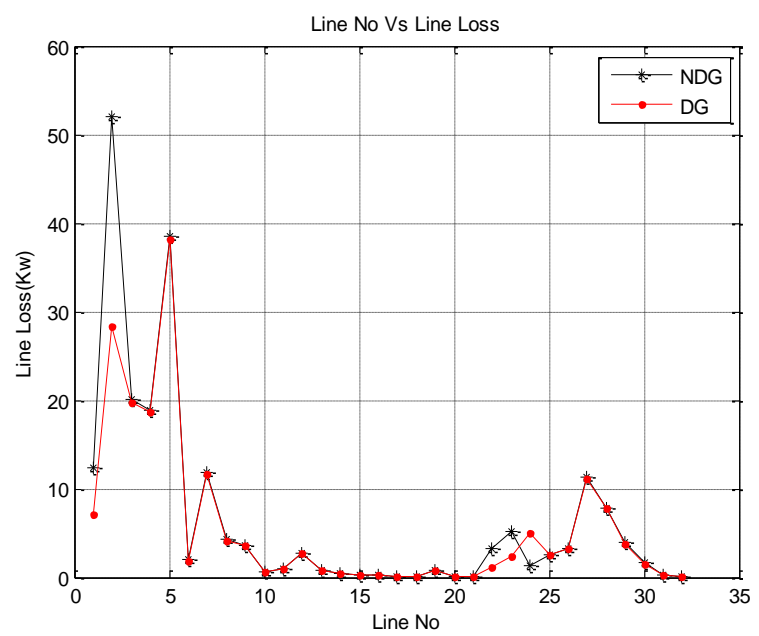

Fig. 5. Line loss with and without placement of DG at bus no. 25
Table 2 VSNI table

\begin{tabular}{|c|c|c|c|}
\hline $\begin{array}{c}\text { Bus } \\
\text { No }\end{array}$ & $\begin{array}{c}\text { Real Power } \\
\text { Demand } \\
\text { (Kw) }\end{array}$ & $\begin{array}{c}\text { Reactive power } \\
\text { Demand } \\
\text { (Kvar) }\end{array}$ & $\begin{array}{c}\text { Voltage } \\
\text { Stability } \\
\text { Node } \\
\text { Indicator } \\
\text { (VSI) }\end{array}$ \\
\hline 1 & 0 & 0 & 0 \\
\hline 2 & 100 & 60 & 0.0316 \\
\hline 3 & 90 & 40 & 0.0304 \\
\hline 4 & 120 & 80 & 0.0361 \\
\hline 5 & 60 & 30 & 0.0259 \\
\hline 6 & 60 & 20 & 0.0265 \\
\hline 7 & 200 & 100 & 0.0501 \\
\hline 8 & 200 & 100 & 0.0547 \\
\hline 9 & 60 & 20 & 0.0286 \\
\hline 10 & 60 & 20 & 0.0290 \\
\hline 11 & 45 & 30 & 0.0251 \\
\hline 12 & 60 & 35 & 0.0291 \\
\hline 13 & 60 & 35 & 0.0319 \\
\hline 14 & 120 & 80 & 0.0430 \\
\hline 15 & 60 & 10 & 0.0296 \\
\hline 16 & 60 & 20 & 0.0300 \\
\hline 17 & 60 & 20 & 0.0312 \\
\hline 18 & 90 & 40 & 0.0372 \\
\hline 19 & 90 & 40 & 0.0367 \\
\hline 20 & 90 & 40 & 0.0324 \\
\hline 21 & 90 & 40 & 0.0307 \\
\hline 22 & 90 & 40 & 0.0313 \\
\hline 23 & 90 & 50 & 0.0308 \\
\hline 24 & $\mathbf{4 2 0}$ & $\mathbf{2 0 0}$ & $\mathbf{0 . 0 6 9 4}$ \\
\hline 25 & $\mathbf{4 2 0}$ & $\mathbf{2 0 0}$ & $\mathbf{0 . 0 7 0 4}$ \\
\hline 26 & 60 & 25 & 0.0261 \\
\hline 27 & 60 & 25 & 0.0273 \\
\hline 28 & 60 & 20 & 0.0280 \\
\hline 29 & 120 & 70 & 0.0411 \\
\hline 30 & $\mathbf{2 0 0}$ & $\mathbf{6 0 0}$ & $\mathbf{0 . 0 6 3 1}$ \\
\hline 31 & 150 & 70 & 0.0473 \\
\hline 32 & 210 & 100 & 0.0546 \\
\hline 33 & 60 & 40 & 0.0296 \\
\hline
\end{tabular}

\section{B. Case B (DG placement at bus no 24)}

From the VSNI table, it is clear that bus no 24 is the most critical or weakest bus of the system. This weakest bus identified as the optimal DG allocation point. Further, DG size is computed by using CISS technique. 


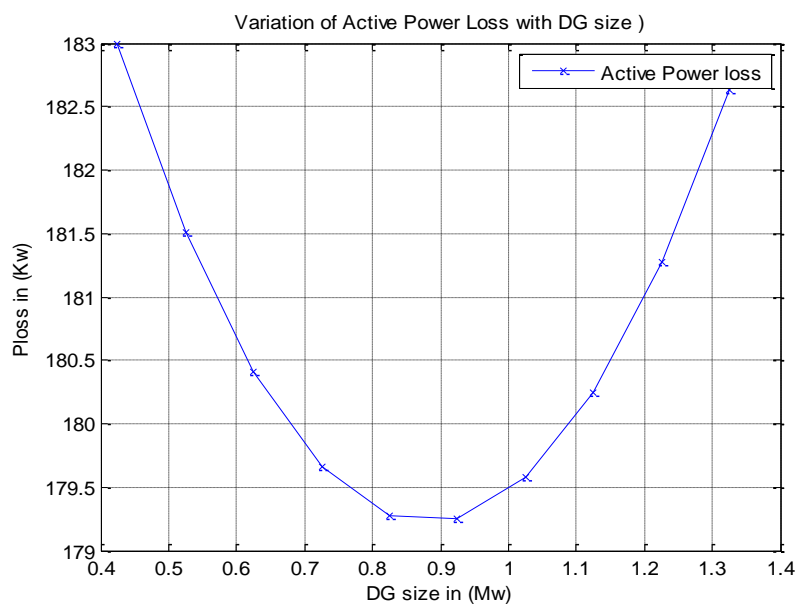

Fig. 6. Power loss curve with step increment of DG size at bus no. 24

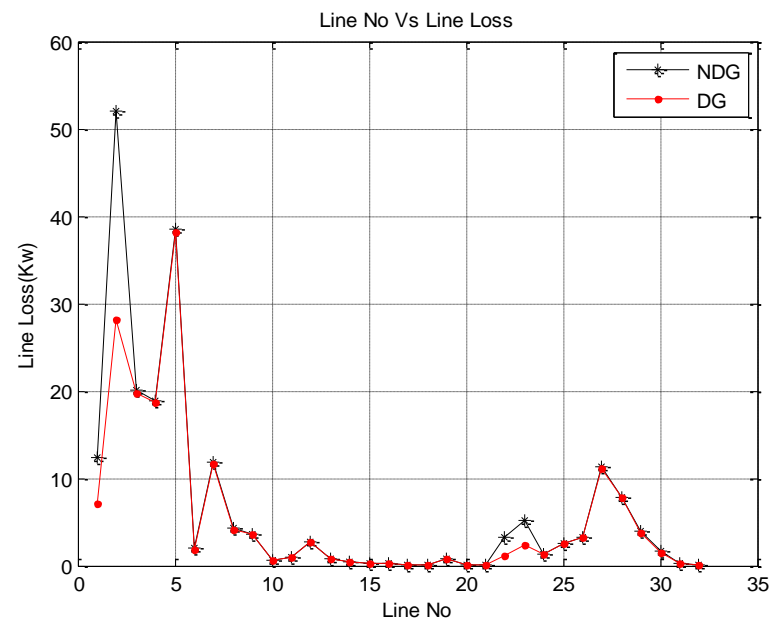

Fig. 7. Line loss with and without placement of DG at bus no. 24

\section{Case C (DG placement at bus no: 30$)$}

To examine the efficacy of the proposed technique, it is applied to $12.66 \mathrm{kV}, 3.72 \mathrm{Mw}$ and 2.3 Mvar RDS consisting of 33 buses. Further, after application of load flow the real power losses incurred by the system before placement of DGs is $210 \mathrm{~kW}$. To reduce the total power loss of the system DGs are placed at different locations as shown in Table. 3. The optimal allocation point is computed by using (11). After computing VSIN at all buses, the three locations i.e. bus no 25, 24 and 30 identified as the most critical bus. To determine the optimum size, CISS technique is applied on all the critical buses.

From Fig. 4, 6 and 8, shows the curve between DG size and total power loss. It is basically follow a parabolic curve, first the total loss decreases and then increases. While selecting DG size, appropriate step size should be chosen carefully. DG size should not exceed the optimum value, above optimum value the total active power loss of the system increases. As a result, system operates in poor voltage regulation and efficiency.

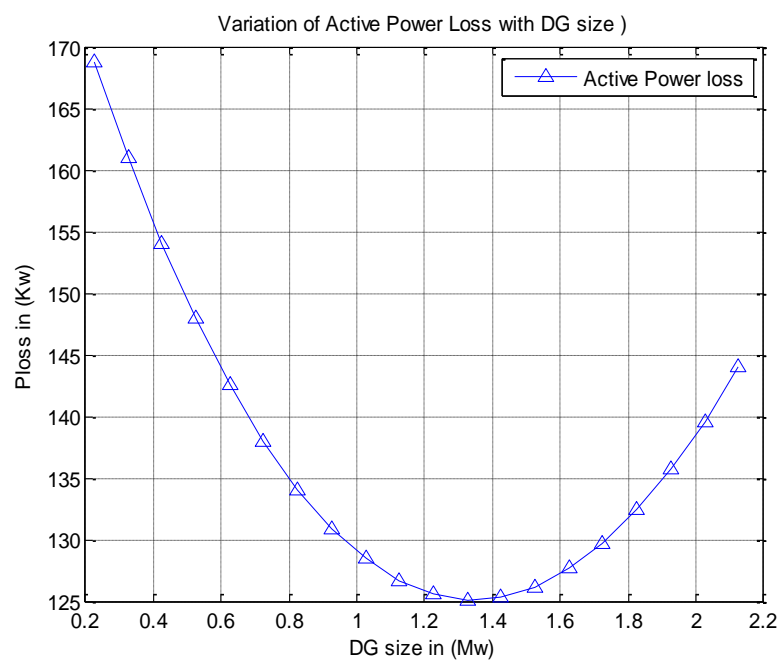

Fig. 8. Power loss curve with step increment of DG size at bus no. 30

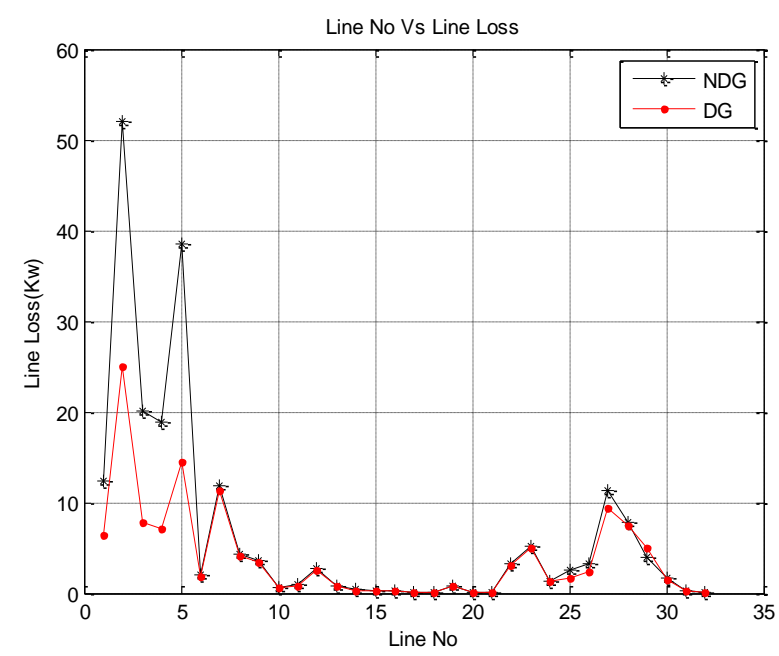

Fig. 9. Line loss with and without placement of DG at bus no. 30

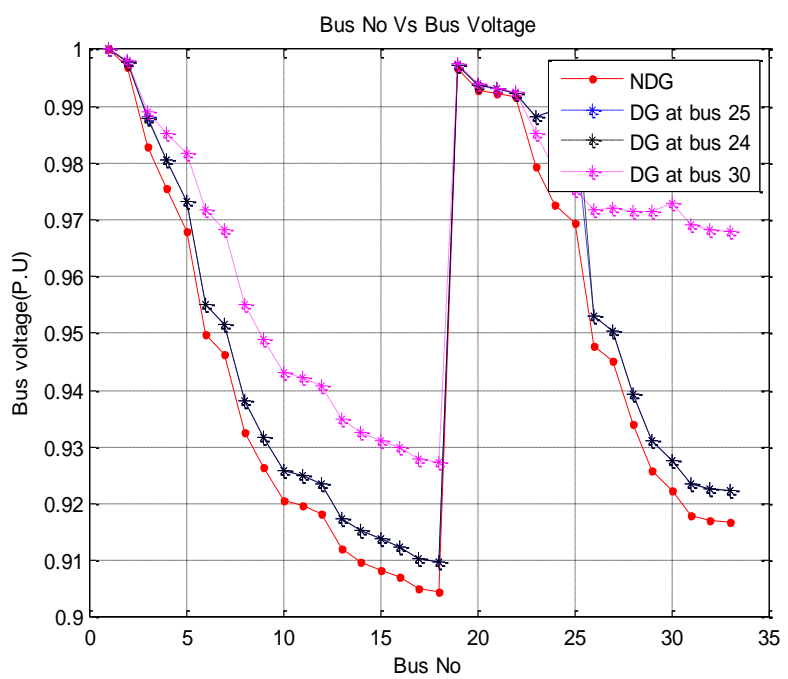

Fig. 10. Comparison of voltage scenarios at different optimal locations. 
Table 3 Active power loss scenario after placement of DG at different optimal locations

\begin{tabular}{cccc}
\hline $\begin{array}{c}\text { Active power } \\
\text { loss before } \\
\text { DG }\end{array}$ & $\begin{array}{c}\text { Active power loss } \\
\text { after DG }\end{array}$ & $\begin{array}{c}\text { Optimal } \\
\text { Locations (Bus } \\
\text { no) }\end{array}$ & $\begin{array}{c}\text { DG size } \\
\text { (Mw) }\end{array}$ \\
\hline 210.7929 & 179.2400 & 25 & 0.920 \\
210.7929 & 175.3113 & 24 & 0.925 \\
210.7929 & 125.1074 & 30 & 1.325 \\
\hline
\end{tabular}

From Fig. 5, 7 and 9 it clear that after placement of DG at optimal locations, the total active power loss reduced in 33bus radial distribution system. Finally, Fig. 10 shows the comparison of voltage profile at different optimal locations.

\section{CONCLUSION}

In this paper, a mixed analytical method is presented on the impact of dispersed generation in RDS. In this method, VSNI and CISS were used to determine the exact location and compute the size of DGs respectively. Proposed method was tested for 33- bus RDS to reduce active power losses and improve voltage profile at each node. The results showed that clearly indicates that case C (allocation of DG at bus no 30) is found to be most appropriate location in minimizing the total active power loss and improving node voltage as compared to the other cases considered.

\section{REFERENCES}

[1] W. H. Kersting, Distribution system modeling and analysis: CRC press, 2006.

[2] K. Zou, A. P. Agalgaonkar, K. M. Muttaqi, and S. Perera, "Distribution system planning with incorporating DG reactive capability and system uncertainties," IEEE Transactions on Sustainable Energy, vol. 3, pp. 112-123, 2012.

[3] P. P. Barker and R. W. De Mello, "Determining the impact of distributed generation on power systems. I. Radial distribution systems," in Power Engineering Society Summer Meeting, 2000. IEEE, 2000, pp. 1645-1656.

[4] E. Bompard, E. Carpaneto, G. Chicco, and R. Napoli, "Convergence of the backward/forward sweep method for the load-flow analysis of radial distribution systems," International Journal of Electrical Power \& Energy Systems, vol. 22, pp. 521-530, 2000.

[5] J.-H. Teng, "A direct approach for distribution system load flow solutions," IEEE Transactions on power delivery, vol. 18, pp. 882887, 2003.

[6] T. Ackermann, G. Andersson, and L. Söder, "Distributed generation: a definition1," Electric power systems research, vol. 57, pp. 195204, 2001

[7] G. Celli, E. Ghiani, S. Mocci, and F. Pilo, "A multiobjective evolutionary algorithm for the sizing and siting of distributed generation," IEEE Transactions on power systems, vol. 20, pp. 750$757,2005$.

[8] C. L. Borges and D. M. Falcao, "Optimal distributed generation allocation for reliability, losses, and voltage improvement," International Journal of Electrical Power \& Energy Systems, vol. 28, pp. 413-420, 2006.

[9] D. Singh, D. Singh, and K. Verma, "Multiobjective optimization for DG planning with load models," IEEE transactions on power systems, vol. 24, pp. 427-436, 2009.

[10] M. Gandomkar, M. Vakilian, and M. Ehsan, "A combination of genetic algorithm and simulated annealing for optimal DG allocation in distribution networks," in Electrical and Computer Engineering, 2005. Canadian Conference on, 2005, pp. 645-648.

[11] M. H. Moradi and M. Abedini, "A combination of genetic algorithm and particle swarm optimization for optimal DG location and sizing in distribution systems," International Journal of Electrical Power \& Energy Systems, vol. 34, pp. 66-74, 2012.
[12] A. Soroudi and M. Afrasiab, "Binary PSO-based dynamic multiobjective model for distributed generation planning under uncertainty," IET renewable power generation, vol. 6, pp. 67-78, 2012.

[13] K. Vinothkumar and M. Selvan, "Fuzzy embedded genetic algorithm method for distributed generation planning," Electric Power Components and Systems, vol. 39, pp. 346-366, 2011.

[14] S. Ganguly, N. Sahoo, and D. Das, "Multi-objective particle swarm optimization based on fuzzy-Pareto-dominance for possibilistic planning of electrical distribution systems incorporating distributed generation," Fuzzy Sets and Systems, vol. 213, pp. 47-73, 2013.

[15] A. El-Zonkoly, "Optimal placement of multi-distributed generation units including different load models using particle swarm optimisation," IET generation, transmission \& distribution, vol. 5, pp. 760-771, 2011.

[16] F. S. Abu-Mouti and M. El-Hawary, "Optimal distributed generation allocation and sizing in distribution systems via artificial bee colony algorithm," IEEE transactions on power delivery, vol. 26, pp. 20902101, 2011.

[17] M. Kowsalya, "Optimal size and siting of multiple distributed generators in distribution system using bacterial foraging optimization," Swarm and Evolutionary computation, vol. 15, pp. $58-65,2014$

[18] A. El-Fergany, "Optimal allocation of multi-type distributed generators using backtracking search optimization algorithm," International Journal of Electrical Power \& Energy Systems, vol. 64, pp. 1197-1205, 2015.

[19] M. Junjie, W. Yulong, and L. Yang, "Size and location of distributed generation in distribution system based on immune algorithm," Systems Engineering Procedia, vol. 4, pp. 124-132, 2012.

[20] J. A. M. García and A. J. G. Mena, "Optimal distributed generation location and size using a modified teaching-learning based optimization algorithm," International journal of electrical power \& energy systems, vol. 50, pp. 65-75, 2013.

[21] D. Q. Hung and N. Mithulananthan, "Multiple distributed generator placement in primary distribution networks for loss reduction," IEEE Transactions on industrial electronics, vol. 60, pp. 1700-1708, 2011. 